\title{
A tradição épica na hora da "lusofonia horizontal". Uma viagem à Índia de Gonçalo M. Tavares face a outras vozes poéticas da língua portuguesa
}

\author{
Ewa A. Łukaszyk*
}

\section{Resumo}

O artigo contribui para o estudo da evolução da lusofonia, desde a sua formação política nos finais do século passado até uma nova realidade observada por José Eduardo Agualusa. A primeira formulação implicou, segundo Alfredo Margarido, um retorno ao período dos Descobrimentos, que efetivamente se deu, ao nível simbólico, com a retomada irónica do modelo camoniano por Gonçalo M. Tavares. A suposta "horizontalidade" da nova lusofonia é discutida através do confronto de Uma viagem à Índia com outras ressonâncias épicas, presentes na poesia de Tony Tcheka, Conceição Lima, Filinto Elísio e Afonso Cruz. No rastro da teoria de literatura menor de Gilles Deleuze e Félix Guattari, fala-se da "desertificação" da tradição épica que perde a conotação gloriosa; em consequência deste processo, o horizonte fechado da literatura hegemónica abre-se para novas ligações.

Palavras-chave: Lusofonia. Poesia épica. Literatura menor. Intertextualidade.

* CY Advanced Studies - Cergy-Paris Université (França). Antiga professora catedrática da Universidade de Varsóvia (Polónia). Especializada em estudos portugueses e literatura comparada. ORCID: 0000-0001-9969-0459. 


\title{
The epic tradition at the time of "horizontal Lusophony". Uma viagem à Índia of Gonçalo M. Tavares in confrontation with other Portuguese- speaking poetic voices
}

\begin{abstract}
The article is a contribution to the study of the evolution of Lusophony, from its political formation in the last decade of the $20^{\text {th }}$ century till the new reality observed by José Eduardo Agualusa. The first formulation implied, according to Alfredo Margarido, a return to the period of Maritime Discoveries; such a return effectively happened, on the symbolic level, with the ironic re-elaboration of the literary model given by Camões in Uma viagem à Índia by Gonçalo M. Tavares. The alleged "horizontal" dimension of the new Lusophony is debated through the confrontation of Tavares with the epic resonances of other poetical voices: Tony Tcheka, Conceição Lima, Filinto Elísio and Afonso Cruz. Following the theory of minor literature formulated by Gilles Deleuze and Félix Guattari, the author speaks of a "desertification" of the epic tradition that loses its glorious connotations. As a consequence of this process, the closed horizon of hegemonic literature opens up for new connectivities.
\end{abstract}

Keywords: Lusophony. Epic poetry. Minor literature. Intertextuality.

Recebido em: 24/07/2020 // Aceito em: 06/12/2020 


\section{Pretexto}

$\mathrm{Na}$ entrada do seu diário O paraíso e outros infernos, correspondente à segunda-feira, 1 de Junho de 2015, José Eduardo Agualusa escreveu: "Estamos criando algo a que podemos chamar lusofonia horizontal: um espaço de língua portuguesa em que todas a partes participam de forma livre, em situação de igualdade, sem dominados nem dominadores" (AGUALUSA, 2018, p. 46). Poderia ser um comentário sobre a nova literatura em português. No entanto, o caso da vida real que o provocou não teve nada que ver com a poesia. Foi a situação em que Kalaf Epalanga, o futuro autor do livro de crónicas $\mathbf{O}$ angolano que comprou Lisboa (por metade do preço), recebera a proposta de adquirir o restaurante lisboeta em que tinha acabado de jantar. Assim, a "vingança do colonizado", que supostamente passou a ser capaz de oferecer soluções económicas na época da crise, teria saldado os ressentimentos, marcando o fim da época póscolonial.

A aquisição da ex-metrópole por metade do preço não passa, evidentemente, de uma broma. No entanto, o conceito de "lusofonia horizontal" nascido dessa situação anedótica merece ser estudado e desenvolvido porque fornece uma alternativa útil ao discurso de subalternidade na formulação introduzida por Gayatri Spivak no famoso ensaio Pode o subalterno falar?, inicialmente publicado no jornal Wedge (SPIVAK, 1985). Em vez da formulação post-marxista das relações do poder, que poderia ser traduzida por um diagrama que se desenvolve do alto para baixo (opressão) ou do baixo para alto (resistência), é urgente a criação duma linguagem analítica da troca, reciprocidade, coexistência e colaboração opcional que poderia desenvolver- 
A tradição épica na hora da "lusofonia horizontal". Uma viagem à Índia de Gonçalo M. Tavares face a outras vozes poéticas da língua portuguesa

se numa rede horizontal de parceiros independentes. Cada um deles tem o seu próprio universo local, com recursos nele existentes, o seu próprio passado e legado que dele deriva, o seu próprio campo problemático que pode coincidir, ou não, com os assuntos prioritários de outrem. No modo de pensar horizontal, os pobres e os ricos, os herdeiros de tradições literárias maiores, com pretensões universalizantes, e os que apenas possuem literaturas e literacias incipientes seriam encarados não numa perspetiva de comparação valorizante, mas sim numa perspetiva de sobrevivências paralelas. A criação poética, em cada caso, seria uma luta contra o peso dos legados recebidos, contra as insuficiências localizadas - negatividades de natureza variável, mas tratados como a matéria prima da criação literária. $\mathrm{Na}$ formulação de Gilles Deleuze e Félix Guattari do famoso ensaio Kafka: Para uma literatura menor, o desafio da literatura é sempre o de "encontrar o seu próprio ponto de desenvolvimento, o seu patoá, o seu próprio terceiro mundo, o seu próprio deserto" (DELEUZE, GUATTARI, 2003, p. 42).

Tratar os economicamente mais dotados em pé de igualdade com os pobres, equiparar os que beneficiam do conforto dos sistemas democráticos e os que suportam o peso das ditaduras, os que podem viajar livremente e os que sofrem o confinamento nas fronteiras do próprio país, tudo isso parece eticamente questionável. No entanto, a poesia nasce do confronto com adversidade; o seu aparecimento não é facilitado pela suficiência material ou maior liberdade intelectual. Antes pelo contrário, a grande literatura deriva, não raramente, das condições de opressão política, económica e social. É precisamente a maneira de vencer a subalternidade que muitas vezes faz um grande escritor. Por outro lado, a criação literária é um ato de participação na rede 
horizontal da troca intertextual que se desenvolve num espaço simbólico, regido pelas leis não-marxistas.

\section{No rasto da crítica da "lusofonia vertical"}

Será que hoje em dia a troca cultural na esfera da língua portuguesa opera verdadeiramente em condições de igualdade dos parceiros, sem pretensão de hegemonia, sem hierarquias crescendo na direção vertical em vez de horizontal? O trabalho intelectual de tais pensadores como Boaventura Souza Santos, inovando na base da teoria pós-colonial, ou Eduardo Lourenço, debruçando-se nos meandros da formação mítica portuguesa, contribuiu para uma mudança profunda. A lusofonia, entendida como um projeto de política cultural lançado nos anos `90 do século passado e dirigida, em primeiro lugar, aos países africanos que formavam o império colonial português apenas duas décadas antes, carecia, sem dúvida, duma tal dimensão horizontal. $\mathrm{Na}$ formulação oriunda daquele momento histórico, o projeto lusófono cedo passou a ser censurado como um intento de neo-colonização cultural, cobrindo, com a abstrata noção do "destino histórico" e da suposta "comunidade da fala", a ausência de soluções viáveis e da ajuda efetiva para a África. Já em 2000, Alfredo Margarido falou do "sopro gélido, muito necrofílico" (MARGARIDO, 2000, p. 5) que o novo projeto exalava. Uma das razões dessa crítica foi precisamente a desproporção do poder económico e das oportunidades de ação de que os parceiros lusófonos dispunham. De facto, para os seus críticos assim como para os seus defensores bem-intencionados, a lusofonia foi uma estruturação do espaço simbólico e criativo que supunha um diagrama vertical, uma hierarquia dos fortes e 
A tradição épica na hora da "lusofonia horizontal". Uma viagem à Índia de Gonçalo M. Tavares face a outras vozes poéticas da língua portuguesa

dos fracos, dos ex-dominados e dos ex-dominadores, agora com a obrigação moral de ajudar. Por causa dessa estrutura profunda, a lusofonia preservava, em vez de liquidar, as identificações subalternas herdadas da época colonial.

\section{Para a "desertificação" da herança épica}

$\mathrm{Na}$ diagnose crítica de Margarido, Portugal, enquanto lançador da lusofonia, "foi remetido para o século XV-XVI, e só aí encontraria razões para existir" (MARGARIDO, 2000, p. 5). No entanto, o desafio da literatura, na formulação de Deleuze e Guattari, seria o de encontrar o metafórico "deserto", o revés desse retorno a uma época que se pretendia gloriosa. E é curioso observar que esse retorno ao século XVI atualmente se deu: foi elaborado poeticamente, embora tenha adotado um sentido que o crítico da lusofonia provavelmente não teria antecipado. A poesia em português escrita nas últimas duas décadas é rica em ressonâncias críticas da dicção épica da expansão marítima que constituiu uma espécie de pré-história ou um momento fundador do espaço lusófono. É um excelente ponto de partida para a busca da hipotética "lusofonia horizontal".

O exemplo talvez mais evidente do retorno ao século XVI é o extenso poema Uma viagem à Índia, de Gonçalo M. Tavares. Em vez da celebração da época gloriosa, é um intento de "desertificação" da tradição herdada, em que a literatura portuguesa encontra, quase num sentido literal, "o seu próprio terceiro mundo", a sua condição de marginalidade, desfasamento e até uma incompatibilidade essencial em relação à modernidade. Gonçalo M. Tavares retomou o paradigma camoniano narrando, em dez cantos, uma jornada antiépica, resultado duma 
contaminação de Os Lusíadas por um modelo moderno, o de Ulisses de James Joyce. Presumivelmente, é por isso que o herói se chama Bloom e vislumbra um retorno ao eterno feminino, ao mesmo tempo universalizado e particularizado na figura duma prostituta, um eco da figura de Molly. Aparentemente, no Canto $\mathrm{X}$, Gonçalo M. Tavares recupera para o seu herói o famoso "yes", a afirmação final de Ulisses:

E Bloom olha em redor e sente-se feliz.

Num bordel perfeito, pode o homem que procurou o seu Espírito na Índia sentir-se tranquilo? A resposta é sim. (TAVARES, 2010, p. 418).

Mas, por outro lado, Bloom também é um marginal da modernidade, um homem primitivo que não a alcança plenamente; não é capaz de moderar os seus impulsos nem aceitar a definição moderna dos direitos de mulher. Acaba antes por esmagar-lhe a cabeça com uma pedra e atirar o seu corpo para um lago. É só depois desta agressão final contra o feminino (em vez das núpcias carnais da velha versão camoniana) que pode regressar a Lisboa. Por outro lado, a viagem à procura de sabedoria conduz à descoberta do tédio, codificado, mais uma vez, à maneira bem portuguesa, mas sem referência à dimensão gloriosa da mitologia nacional: não a do período de expansão culminando na visão da harmonia das esferas, mas sim a de António Nobre no poema "Ao canto do lume" incluído, em 1892, na coletânea Só: "Viajar? Ilusão. Todo o planeta é zero" (NOBRE, 1892, p. 119).

A leitura de Uma viagem à Índia enquanto um projeto poético lusófono certamente não é a mais evidente. Bloom não é um membro da "comunidade da fala" que poderia juntar 
A tradição épica na hora da "lusofonia horizontal" . Uma viagem à Índia de Gonçalo M. Tavares face a outras vozes poéticas da língua portuguesa

Portugal ao vasto mundo africano e atlântico. Antes pelo contrário, aparece como um português eminentemente nãolusófono sem ser um europeu de pleno direito. Confronta-se com o Oriente que supõe possuidor duma sabedoria impossível de adquirir nas circunstâncias normais, nomeadamente as da modernidade ocidental. Por outro lado, Uma viagem à Índia marca o momento de desconstrução final da mitologia nacional portuguesa, que tanta importância tinha ainda no tempo de Eduardo Lourenço. A inscrição europeia, deficiente, mas já sem alternativa, de Bloom Tavariano indica a distância que separa a cultura portuguesa implicada no poema publicado em 2010 da que originou o ensaio Nós e a Europa, ou as duas razões, de Eduardo Lourenço, em 1988. Sem ser plenamente o homem moderno, Bloom não se associa com nenhum polo oposto à Europa e à modernidade, não forma nenhuma "segunda razão". O seu tédio final marca uma posição marginal sem potencial de ação transformadora em relação ao mundo.

No caminho percorrido, Bloom não passa pelo espaço africano ou atlântico, mas antes pelo contrário, por várias cidades europeias. Afinal, o herói alcança o seu destino de avião, sem a necessidade de circum-navegar a África. No entanto, entre vários achamentos intelectuais que faz, também há uma verdade que diz respeito à língua e à comunidade criativa da fala. É uma verdade que poderia ser interpretada como o oposto da visão da lusofonia cripto-neo-colonial, entendida como o retorno espetral dos contornos do império colonial abolido:

A língua não é proprietário que soma metros quadrados a arfar de satisfação. A língua aumenta quando alguém escreve ou diz algo portador de uma levíssima corrupção da norma (...). A língua aumenta com os erros exatos, 
não com maiores desenhos nos mapas. (TAVARES, 2010, p. 170-171).

Sendo assim, se quisermos buscar um sentido lusófono no poema de Tavares, a lusofonia seria encarada aqui como um projeto de porvir que devia expressar-se numa esfera em que as coordenadas da literacia cultural dominante foram transformadas num campo de subversão no sentido de Deleuze e Guattari. Em Kafka: Para uma literatura menor, os pensadores franceses disseram que "uma literatura menor não pertence a uma língua menor, mas, antes, à língua que uma minoria constrói numa língua maior. E a primeira característica é que a língua, de qualquer modo, é afetada por um forte coeficiente de desterritorialização" (DELEUZE, GUATTARI, 2003, p. 38). O resultado do processo da reinvenção poética acaba por revitalizar, em vez de destruir, a esfera da tradição literária dominante. Por isso, a "lusofonização" da literatura portuguesa não corrompe a sua posição duma tradição cultural hegemónica. Mesmo se o Bloom português se transforme numa figura dum marginal europeu, o poema de Tavares contribui para a projeção global da literatura em português no campo da literatura mundial, um estatuto que nenhuma literatura meramente nacional (enclausurada no seu próprio idioleto mítico) poderia alcançar. É por isso que Uma viagem à Índia acaba por ser um projeto universalizante antes que pluriversalizante. No entanto, a palavra pluriversal, como vamos ver, reaparece com as vozes poéticas africanas, formando um contraponto à literatura portuguesa na sua inscrição europeia. 
A tradição épica na hora da "lusofonia horizontal". Uma viagem à Índia de Gonçalo M. Tavares face a outras vozes poéticas da língua portuguesa

\section{No espaço da circulação obstruída}

No ensaio citado, Alfredo Margarido sublinhava a essencial falsidade da lusofonia enquanto projeto político, porque o "espaço lusófono" projetado não era um espaço de livre circulação das pessoas; continuava sendo um espaço de exclusão dos lusófonos africanos que de facto não participavam no mesmo "destino histórico" da "comunidade da fala", mas sim num destino $a$ parte, definido pela existência de fronteiras e fossos económicos. Entretanto, Gonçalo M. Tavares acentua a inscrição do seu herói na Europa caracterizada precisamente como um espaço de circulação perfeita, livre de qualquer obstrução:

onde as canalizações por dentro das casas e os aviões nos céus se acompanham numa misteriosa simetria. (TAVARES, 2010, p. 111).

É precisamente esta facilidade de circulação que diferencia o sujeito europeu do sujeito lusófono, tal como o resumiu o poeta guineense Tony Tcheka na figura de Tchiku. Assim como Bloom é uma incarnação dos impulsos que lançam os europeus aos caminhos do mundo, Tchiku resume o desejo de migração como o projeto biográfico dominante entre os homens nascidos na Guiné-Bissau, o país mais pobre da projetada lusofonia e um dos países mais pobres do mundo:

Tchiku
tem-tem
na bola de trapos
vida tem-tem
que nada tem

Entre quedas

e cambalhotas 
Tchiku foi na onda
terra-branco rek (TCHEKA, 2008, p. 56).

Eventualmente, o impulso que lança o herói africano na sua demanda da "terra dos brancos" podia ser qualificado como tédio: o tédio duma existência sem perspetivas, à margem do mundo em mudança e desenvolvimento. As circunstâncias económicas, políticas e sociais de Bloom (o tedioso europeu) e Tchiku (o tedioso guineense) são separadas por um fosso. No entanto, a relação entre essas duas tonalidades poéticas e existenciais do mesmo afeto pode ser vista numa perspetiva horizontal. A leitura paralela dos idiomas de Gonçalo M. Tavares e Tony Tcheka põe em relevo tanto a desproporção e a desigualdade das circunstâncias, como a coexistência e a contiguidade dos conceitos chaves no espaço lusófono.

Entretanto, do outro recanto do Atlântico, a voz poética de Conceição Lima traça mais uma "Anti-epopeia", parte da coletânea A dolorosa raiz do micondó:

Aquele que na rotação dos astros e no oráculo dos sábios buscou de sua lei e mandamento a razão, a anuência, o fundamento (...) Aquele a quem a voz da tribo ungiu chamou rei, de poderes investiu

Por panos, por espelhos, por missangas por ganância, avidez, bugigangas as portes da corte abriu de povo seu reino exauriu (LIMA, 2006, p. 20).

Neste regresso ao tom épico, distante, pela sua seriedade, do projeto essencialmente irónico de Gonçalo M. Tavares, a poetisa 
A tradição épica na hora da. "lusofonia horizontal" . Uma viagem à Índia de Gonçalo M. Tavares face a outras vozes poéticas da língua portuguesa

de São Tomé estabelece um novo campo de renegociação que já se diferencia do tipicamente pós-colonial. É um retorno crítico à questão da participação africana no comércio escravagista promovido pelos europeus, já que a figura mencionada no poema poderia ser identificada, por exemplo, com o Mansa de Kaabú, o maior fornecedor dos escravos nas feitorias portuguesas da África ocidental. O poema soa como um eco de Sá de Miranda que no século XVI criticava as opções comerciais e expansionistas tomadas pelos portugueses na carta poética dirigida "A António Pereira, senhor de Basto":
(...) temo-me de Lisboa
Que ao cheiro desta canela
O reino nos despovoa. (SÁ DE MIRANDA, 1977, vol. 2, p. 87).

O duplo despovoamento, o causado pelo impulso expansionista e o do comércio negreiro devastador, certamente não pode ser reduzido ao denominador comum em termos vivenciais; não formou destinos paralelos. No entanto, forma uma horizontalidade do retorno não a um passado histórico - em que a distribuição dos papeis entre os comerciantes e os que foram reduzidos ao objeto da troca comercial não se pode equiparar -, mas sim à esfera simbólica que admite intertextualidades cruzadas e permite situa-las em plano de igualdade.

No livro mais recente, $\mathbf{O}$ país de Akendenguê, a dicção poética de Conceição Lima ficou mais condensada, elíptica, como se afirmasse a sua vocação para o silêncio. Em "Erosão", este é o termo de todos os impérios:

Como o silêncio corrói as pedras da fortaleza assim o sussurro infiltra as paredes e adensa os semblantes

(LIMA, 2011, p. 54). 
Também é o termo da "Circum-navegação", em que o momento do regresso dos barcos é apenas celebrado pelo silenciamento de todas as coisas:

Adormecem os grilos.

Uma criança escuta a concavidade de um búzio. (LIMA, 2011, p. 106).

No ruído branco do interior desse búzio poder-se-ia escutar o mutismo final do império, carregado de vozes silenciadas, que já não encontraram a sua expressão na lusofonia, "um legado / de híbridas palavras" deixado nas ilhas, que Conceição Lima menciona em "Afroinsularidade" (LIMA, 2006, p. 39). Ao mesmo tempo, abre-se um novo campo da palavra para a busca duma expressão "horizontal", sem diferenciar o estatuto dos participantes da mesma maneira que os estatutos foram diferenciados na História e continuam diferenciados no porvir económico e político.

Lida na perspetiva do conceito de literatura menor de Deleuze e Guattari, a recente poesia em português, com todo o seu tédio, pessimismo, dimensão anti-épica, triunfo do silêncio, inquietação pela condição masculina marcada pela incapacidade de transformar o mundo, pode, apesar de tudo, ser interpretada como a saída do impasse herdado das gerações anteriores. $\mathrm{Na}$ dicção peculiar de Deleuze e Guattari, "fez-se a ligação com toda uma toca subterrânea e com todas as saídas desta toca" (DELEUZE, GUATTARI, 2003, p. 29). Redesenhou-se o mapa do espaço simbólico, que agora deixou de refletir os contornos do império passado, como a fotografia do pai que ocultava e "edipianizava" o mapa-mundo em Kafka. 
A tradição épica na hora da "lusofonia horizontal", Uma viagem à Índia de Gonçalo M. Tavares face a outras vozes poéticas da língua portuguesa

\title{
Em busca duma nova globalidade
}

A poesia que poderia dar conteúdo à noção de "lusofonia horizontal", assaz acidentalmente cunhada por Agualusa, tem uma pronunciada vocação pluriversal, em que a língua portuguesa entra em negociação permanente com outros sistemas de comunicação: vários crioulos, assim como línguas autóctones subjacentes ao que antes fora conceptualizado como "o mundo português". Aliás, o citado poema de Tony Tcheka também possui uma versão paralela em crioulo, publicada em 1996:

\author{
Tchiku ten-ten \\ na bola di meia \\ bida di ten-ten \\ di kin ku ka ten...
}

(TCHEKA, 1996, p. 27).

Ao mesmo tempo, relativamente cerca no espaço geográfico da lusofonia (se tem alguma importância quão cerca as ilhas de Cabo Verde ficam da Guiné-Bissau de Tony Tcheka), a literacia cultural dominante, a que poderia incluir a dicção classicista ou o legado épico do Renascimento, adquire a dimensão mundial em vez de coincidir com a herança nacional de Portugal como o excolonizador. É assim que Filinto Elísio, um poeta cabo-verdiano, joga com a herança clássica já descolonizada e, ao mesmo tempo, globalizada, em que a história da navegação contada nos Lusíadas é um ponto de partida, mas não o de chegada:

Os deuses, em dissídio, como por Olimpo, cogito de Luís Vaz, à sorte de Gama, diziam que à morte de Omerus, no canto de Walcott, era, em tudo, senão Odisseia, a de Ulisses.

Herói, além dos ventos furibundos nos odres, 
nas delícias de Nausicaa, das encantadas, que preso ao mastro, e como em Quixote, Cervantes irou Alonjo Quijano aos moinhos. (ELÍSIO, 2016, p. 53).

Filinto Elísio conduz este jogo já solidamente enraizado no classicismo da geração da revista Claridade, que queria ver nas ilhas da costa ocidental da África o jardim das Hespérides. Ao mesmo tempo, participa na tradição transatlântica dos Caraíbas, com o santa-lucense Derek Walcott. E mais, assim que o poema se desenvolve, vai evocando uma consciência de literatura mundial mais abrangente, tanto nos horizontes geográficos, como no encontro das culturas evocado, entre várias outras, na figura de Omar Khayyam. Forma-se assim um subsistema da literatura mundial em que o português não é o vetor de comunicação privilegiado, dando voz às experiências ou mundividências até pouco silenciadas ou oprimidas, mas sim uma matriz em que se incrustam várias modalidades de comunicação e várias literacias que já não são encaradas como portadoras de prestígio desigual. $\mathrm{O}$ cânone pós-colonial aparece em pé de igualdade com obras clássicas, consideradas de valor "universal", tais como o romance de Cervantes ou, graças a um processo de apropriação orientalista, as quadras de Omar Khayyam. Ainda por cima, o encontro com este novo cânone mundial faz-se numa perspetiva descontraída, jocosa, visível na intenção de paródia que se pode ler no staccato esforçado com que, a custa de ruturas sintáticas frequentes, se pretende imitar o ritmo pausado e solene duma epopeia. Ao mesmo tempo, é uma tentativa poética muito distinta em relação a Uma viagem à Índia, nomeadamente pela tentativa de uma circum-navegação literária que adquire as características dum diagrama desenvolvido na direção horizontal, pela justaposição de referências, uma cadeia de associações, fugindo 
A tradição épica na hora da "lusofonia horizontal". Uma viagem à Índia de Gonçalo M. Tavares face a outras vozes poéticas da língua portuguesa

a absolutização de um só modelo ou referente.

À relativamente tão pouca distância geográfica da GuinéBissau, Filinto Elísio ocupa um lugar muito distante no espaço simbólico em relação ao do Tony Tcheka: o duma enunciação descontraída, mas ao mesmo tempo consciente da sua própria inscrição na literatura global. É uma globalização cultural tomada em positivo, contrastando com uma globalização degradante em que participam os homens guineenses retirados do tédio (na sua versão africana) apenas para serem mobilizados para atividades de caráter ilegal no poema "E nós ficámos!":

\author{
os matchus da incapacidade \\ do nada fazer \\ matchus alérgicos à diferença \\ afoitos ao sangue \\ ao pó branco \\ dá taco - patacon, kumbu, money
}

(TCHEKA, 2005, p. 22).

Afinal, apesar de tanta distância no conteúdo existencial que separava, como antes se tinha demonstrado, o tédio africano do tédio europeu, a visão da condição masculina (a matchundadi na conceptualização crioula de Tony Tcheka) coincide com a essencial incapacidade de Bloom que no final da anti-epopeia de Gonçalo M. Tavares encontra a sua antiga miséria, culpabilidade e ignorância. No explicit do texto, o tédio se transforma numa condição inamovível:

(...) nada que aconteça poderá impedir o definitivo tédio de

Bloom, o nosso herói.

(TAVARES, 2010, p. 463).

O pessimismo que predomina numa grande parte da recente poesia em português pouco tem que ver com o otimismo que o 
projeto lusófono, acentuando a dimensão do porvir, era suposto de introduzir. A consciência do lado sinistro da globalização, antes que a consciência transformadora da "comunidade da fala", predomina também na visão do mundo presente na poesia de Afonso Cruz:

Há uma teia que nos liga, uma conspiração invisível (...)

Quando cai uma mosca numa ponta da teia, a aranha, na outra ponta, sabe o que aconteceu (...) (CRUZ, 2019, p. 68).

O espaço mundial visto como uma gigantesca teia de aranha pressupõe uma conectividade quase perfeita que, no entanto, não se traduz em possibilidades de ação transformadora que $o$ espírito comunitário da lusofonia deveria viabilizar. Em 2015, o vazio das boas intenções foi presentado por Afonso Cruz duma forma elíptica, mas ao mesmo tempo extremamente pungente num pequeno livro ilustrado, A cruzada das crianças, em que a mundividência e mitologia consumista, cuja encarnação mais perfeita é o Pai Natal, não consegue nem salvar o mundo, nem estabelecer nenhuma forma de comunidade autêntica e operante, mesmo se há um desejo explícito de estabelecer laços de solidariedade através da distribuição das prendas do Natal. A primeira lusofonia, criticada por Alfredo Margarido, tinha precisamente este carácter idealista, benévolo, mas ao mesmo tempo ineficiente. O valor transformativo da "lusofonia horizontal", operando no espaço da intertextualidade criadora, em vez de distribuição de ajudas, abre uma via para escapar do impasse. 
A tradição épica na hora da "lusofonia horizontal", Uma viagem à Índia de Gonçalo M. Tavares face a outras vozes poéticas da língua portuguesa

\section{Conclusão}

Segundo Deleuze e Guattari, o essencial da literatura menor consiste em encontrar um caminho onde o simbólico pai não encontrou nenhum. A nova poesia em português, nascida em contextos sem paridade e sem condições de igualdade económica, política ou cultural dadas a priori, busca a sua "horizontalidade" onde só havia condição subalterna, legados dolorosos, vozes silenciadas. É uma literatura nascida da múltipla impossibilidade de escrever (aporias de escrever em português, escrever em crioulo, escrever de outra maneira, não escrever). Os textos dialogam entre si já sem complexos de inferioridade nem de superioridade, encontrando a horizontalidade deste diálogo precisamente na expressão da fraqueza, do tédio, do desconforto, da insuficiência, da ausência do projeto mobilizador, do silêncio que se ergue na ausência das grandes ideologias. A lusofonia "vertical", hierárquica e subalterna, lançada nos anos '90 do século passado, foi o último desses grandes projetos que apenas garantiram uma mobilização inautêntica e de pouca dura. A literatura "horizontal" que se estende no vazio do espaço simbólico abandonado promete uma autenticidade do animal de Deleuze e Guattari. Certamente, o animal não sofre a tentação de reanimar as glórias passadas; confronta o mundo no imediato, com a cabeça erguida, signo do "desejo que se ergue ou se esquiva, e se abre a novas ligações” (DELEUZE, GUATTARI, 2003, p. 22). 
Referências

AgUALUSA, José Eduardo. O Paraíso e Outros Infernos. Lisboa: Quetzal, 2018.

CRUZ, Afonso. A cruzada das crianças - Vamos mudar o mundo. Lisboa: Alfaguara, 2015.

CRUZ, Afonso. Paz traz paz. Lisboa: Companhia das Letras, 2019.

DELEuZE, Gilles, GUATTARI, Félix. Kafka. Para uma literatura menor. Tradução de Rafael Godinho. Lisboa: Assírio / Alvim, 2003.

EPALANGA, Kalaf. O angolano que comprou Lisboa (por metade do preço). Lisboa: Caminho, 2014.

ELÍSIO, Filinto. Zen Limites. Lisboa: Rosa de Porcelana, 2016. LIMA, Conceição. A dolorosa raiz do micondó. Lisboa: Caminho, 2006.

LIMA, Conceição. O país de Akendenguê. Lisboa: Caminho, 2011.

LOURENÇO, Eduardo. Nós e a Europa, ou as duas razões. Lisboa: IN-CM, 1988.

MARGARIDO, Alfredo. A Lusofonia e os Lusófonos. Novos mitos portugueses. Lisboa: Edições Lusófonas, 2000.

MIRANDA, Sá de. Obras completas de Sá de Miranda. Edição de Rodrigues Lapa. Lisboa: Sá da Costa, 1977.

NOBRE, António. Só. Paris: Léon Vanier, 1892.

SPIVAK, Gayatri. Can the subaltern speak? Speculations on widow-sacrifice. Wedge, New York, n. 7/8 (Winter/Spring), p. 120-130, 1985.

SPIVAK, Gayatri. Pode o subalterno falar?. Belo Horizonte: Editora UFMG, 2018. 
A tradição épica na hora da "lusofonia horizontal" , Uma viagem à Índia de Gonçalo M. Tavares face a outras vozes poéticas da língua portuguesa

TAVARES, Gonçalo M. Uma viagem à Índia. Lisboa: Caminho, 2010.

TCHEKA, Tony. Noites de insónia na terra adormecida. Bissau: INEP, 1996.

TCHEKA, Tony. Desesperança no chão de medo e dor. Prefácio de Moema Parente Augel. [S.1.]: Edições Corubal, 2005. TCHEKA, Tony. Guiné sabura que dói. São Tomé e Príncipe: UNEAS, 2008. 